Ann Surg. 2009 July ; 250(1): 134-140. doi:10.1097/SLA.0b013e3181ad85f7.

\title{
Hypothermia and Surgery:
}

\section{Immunologic Mechanisms for Current Practice}

Motaz Qadan, BSc (Hons), MBChB, MRCS (Ed) ${ }^{\star}$, Sarah A. Gardner, BS ${ }^{\star}$, David S. Vitale, BS $^{\star}$, David Lominadze, PhD $\dagger$, Irving G. Joshua, PhD $\dagger$, and Hiram C. Polk Jr, MD $\ddagger$ "Price Institute of Surgical Research, University of Louisville School of Medicine, Louisville, Kentucky

†Department of Physiology and Biophysics, University of Louisville School of Medicine, Louisville, Kentucky

‡Department of Surgery, University of Louisville School of Medicine, Louisville, Kentucky

\section{Abstract}

Objective-To examine cellular and immunologic mechanisms by which intraoperative hypothermia affects surgical patients.

Summary Background Data-Avoidance of perioperative hypothermia has recently become a focus of attention as an important quality performance measure, aimed at optimizing the care of surgical patients. Anesthetized surgical patients are particularly at risk for hypothermia, which has been directly linked to the development of sequelae, such as coagulopathy, infection, morbid myocardial events, and death after surgery. However, many of the underlying immunologic mechanisms remain unclear.

Methods-Venous blood samples from healthy volunteers were exposed for up to 4 hours to various temperatures following the addition of a $1 \mathrm{ng} / \mathrm{mL}$ lipopolysaccharide challenge. Innate immune function, assessed by the ability of monocytes to present antigen and coordinate cytokine release, was determined by qualitative and quantitative measurements of HLA-DR surface expression 2 hours following incubation, and proinflammatory tumor necrosis factor- $\alpha(\mathrm{TNF}-\alpha)$ and anti-inflammatory (IL-10) cytokine release in the first 4 hours.

Results-Monocyte incubation at hypothermic temperatures $\left(34^{\circ} \mathrm{C}\right)$ reduced HLA-DR surface expression, delayed TNF- $\alpha$ clearance, and increased IL-10 release. Conversely, hyperthermia $\left(40^{\circ}\right.$ C) increased monocyte antigen presentation and resulted in rapid decay of TNF- $\alpha$. However, IL-10 release was also increased. Normothermia $\left(37^{\circ} \mathrm{C}\right)$ attenuated IL-10 release following the initial proinflammatory surge.

Conclusion-Hypothermia exerts multiple effects at the cellular level, which impair innate immune function, and are associated with increased septic complications and mortality. These findings provide a physiological basis for perioperative temperature monitoring, which is a valid surgical performance measure that can be used to reduce surgical complications associated with avoidable hypothermia. 
Although the protective effects of fever have been recognized for many decades now, evidence regarding the converse detrimental effects of hypothermia in surgical patients remains relatively novel and continues to emerge. ${ }^{1-3}$

Intraoperative hypothermia, which is thought to occur in as many as $20 \%$ of surgical patients today, results from direct heat loss in a cool operating suite environment and impaired thermoregulation associated with anesthesia. ${ }^{3}$ Hypothermia has been reported to result in delayed wound healing; increased surgical site infection, ${ }^{4}$ prolonged length of hospitalization, ${ }^{4}$ increased myocardial complications, ${ }^{5}$ increased intraoperative blood loss and need for transfusion, which, in turn, worsens hypothermia, ${ }^{6,7}$ delayed recovery from anesthesia, ${ }^{8}$ negative catabolism and nitrogen balance, ${ }^{9}$ increased postoperative discomfort, ${ }^{10}$ and an overall higher mortality. ${ }^{6,11}$ Consequently, perioperative temperature monitoring and avoidance of intraoperative hypothermia are now being recognized as worthy quality improvement measures aimed at optimizing surgical care, along with somewhat more broadly defined measures such as timely antibiotic administration, ${ }^{12}$ venous thromboembolism prophylaxis, ${ }^{13}$ and strict glycemic control. ${ }^{13,14}$ However, despite general acceptance among the surgical community, the mechanisms by which hypothermia exerts its detrimental effects, particularly in the development of infectious sequelae, are not well elucidated.

It has been proposed that hypothermia may predispose to local wound and systemic infection in at least 2 ways. Firstly, hypothermia evokes a thermoregulatory vasoconstriction in skin and subcutaneous vessels to minimize heat loss. In doing so, oxygen delivery, and, therefore, oxygen wound tensions are reduced. The subsequent wound hypoxia has been directly correlated with infective wound events. ${ }^{15-17}$ Secondly, hypothermia has been shown to inhibit T-cell-mediated antibody production and nonspecific neutrophil oxidative killing. ${ }^{18-20}$ Innate immune mechanisms, such as neutrophil oxidative killing, play a key role in preventing infection after exposure to an intraoperative bacterial challenge. A decisive period within a very few hours exists, when inevitable contamination may transform into local or general infection if innate immune defense mechanisms fail to prevail over pathogenic contaminants. 21,22 Consequently, the continuing development of infection among surgical patients, despite appropriate antibiotic use and combined with emerging drug resistance, has led to further focus upon optimizing innate immune mechanisms to minimize infection rate.

In this report, we provide further insight into the immunologic mechanisms underlying hypothermic injury in surgery. Specifically, we investigate 2 key parameters of innate defense mechanisms at varying physiologic temperatures; namely, monocyte antigen presentation via major histocompatibility class II (HLA-DR) surface receptor expression, and cytokine production. Although we describe our findings in the context of surgery, we believe these concepts may be extrapolated to include other entities in medicine, such as pre-transplant organ-preservation, deliberate hypothermic circulatory arrest, and burns and trauma.

\section{MATERIALS AND METHODS}

\section{Protocol}

Following approval of the University of Louisville Institutional Review Board and written, informed consent, up to $15 \mathrm{~mL}$ venous blood samples were collected from a random selection of 15 healthy (8 male), nondiabetic volunteers in EDTA Vacutainers (Becton Dickinson, Franklin Lakes, NJ). Volunteers fasted for a minimum of 6 hours prior to donation. Exclusion criteria included any acute illness and history of immunosuppressive disorders, diabetes mellitus, or any chronic medication. Immediately following venepuncture, blood glucose levels were determined using a Glucometer Elite (Bayer Corporation, Elkhart, IN). Samples were supplemented with $200 \mathrm{mM}$ of $\mathrm{L}$-glutamine at a concentration of $10 \mu \mathrm{L} / \mathrm{mL}$ of whole blood (Sigma Chemical Co., St. Louis, MO). ${ }^{23}$ Aliquots of whole blood $(1 \mathrm{~mL})$ were subsequently 
transferred into Falcon polypropylene culture tubes (Fisher Scientific). An optimal lipopolysaccharide (LPS) concentration of $1 \mathrm{ng} / \mathrm{mL}$, as determined by other studies and confirmed by our pilot experiments, provided the endotoxin challenge immediately prior to incubation (Escherichia coli 0111:B4; Sigma Chemical Co, St. Louis, MO). ${ }^{24}$

Corresponding LPS-treated samples with fasting glucose levels below $120 \mathrm{mg} / \mathrm{dL}$ were incubated at clinically applicable temperatures of $34^{\circ} \mathrm{C}, 37^{\circ} \mathrm{C}$, and $40^{\circ} \mathrm{C}$ in room air $(21 \%$ oxygen) and 5\% carbon dioxide. Samples were incubated for 2 hours to determine monocyte HLA-DR surface expression and cytokine release. ${ }^{25}$ In separate experiments, samples were incubated for intervals of 30, 60, 120, and 240 minutes for time-course analysis of cytokine release following the endotoxin challenge.

Throughout culture, gentle vortex was applied at 45-minute intervals to ensure cellular homogeneity and even exposure to environmental variables. Aliquots of cultured samples (50 $\mu \mathrm{L}$ ) were stained immediately prior to incubation (time 0 ) and following incubation, and were subsequently analyzed to determine baseline and final monocyte HLA-DR expression respectively. Remaining volumes were centrifuged at 3000 RPM for 12 minutes to obtain acellular supernatant, which was stored at $-81^{\circ} \mathrm{C}$ for cytokine analysis.

To ensure that results observed are not due to variation in monocyte number and survival at different incubation temperatures, cells were manually counted using a hemocytometer prior to, and immediately following incubation. Cells were subsequently stained using propidium iodide to determine the percentage of dead monocytes following incubation. $\mathrm{pH}$ levels were also tested prior to, and following monocyte incubation.

\section{Monocyte CD14/HLA-DR Staining and Extraction}

Whole blood samples $(50 \mu \mathrm{L})$ were stained with fluorescein isothiocyanate-labeled antihuman $\mathrm{CD}_{14}{ }^{+}$and phycoerythrin-labeled anti-HLA-DR antibodies (BD Biosciences, La Jolla, CA) to determine monocyte HLA-DR expression. Staining was carried out for 25 minutes in the culture environment, to prevent down- or up-regulation of HLA-DR prior to binding.

Appropriately matched isotype controls were used to determine nonspecific binding thresholds. Manufacturer instructions were closely followed.

Following staining, red blood cell lysis was carried out for 6 minutes using ammonium chloride, potassium bicarbonate, and EDTA (Sigma Chemical Co., St. Louis, MO). Monocytes were pelleted by centrifugation, washed with Dulbecco Phosphate Buffered Saline (Sigma Chemical Co., St. Louis, MO), and fixed in $250 \mu \mathrm{L}$ of $1 \%$ paraformaldehyde solution.

\section{Flow Cytometric Analysis}

Monocyte $\mathrm{CD} 14^{+}$and HLA-DR surface expression were analyzed within 4 hours of cell culture, using a FACSCalibur flow cytometer (Becton Dickinson, San Diego, CA). A total of 20,000 events were acquired. HLA-DR mean channel fluorescence (MCF) was analyzed in CD14+ monocytes using Cell Quest software (Becton Dickinson, San Diego, CA).

\section{Confocal Microscopy}

Following staining and monocyte extraction, $100 \mu \mathrm{L}$ samples were transferred into 8-well culture chambers and mounted on the microscope. Digital images were taken using a laserscanning confocal microscope (Olympus IV1000; objective 100x). The $\mathrm{CD} 14^{+}$marker was visualized using a multiline Argon laser to excite the dye at $496 \mathrm{~nm}$ and emission was observed above $520 \mathrm{~nm}$. The HLA-DR marker dye was similarly excited at $495 \mathrm{~nm}$ and emission observed above $570 \mathrm{~nm}$. Microscope settings were optimized for the brightest images and were kept unaltered during the analysis. 


\section{Cytokine Determinations}

Plasma tumor necrosis factor- $\alpha$ (TNF- $\alpha$ ) and interleukin-10 (IL-10) concentrations were quantified using commercially available enzyme-linked immunosorbent assay kits (eBiosciences, San Diego, CA). All enzyme-linked immunosorbent assay's were carried out in 96-well plates according to manufacturer's instructions. Samples were assayed in duplicate, with either recombinant human TNF- $\alpha$, or IL-10, to generate the standard curve. Enzyme activity was measured at a wavelength of $450 \mathrm{~nm}$ on a SpectraMax Plus384 (Molecular Devices, Sunnyvale, CA) spectrophotometer. Data were generated using Softmax Pro software (Molecular Devices, Sunnyvale, CA) and expressed in $\mathrm{pg} / \mathrm{mL}$. The lower limits of detection for TNF- $\alpha$ and IL-10 were $4 \mathrm{pg} / \mathrm{mL}$ and $2 \mathrm{pg} / \mathrm{mL}$, respectively.

\section{Statistics}

Repeated-measures analysis of variance testing was used to detect significant differences in corresponding samples. This was followed by multiple-comparison testing, using the HolmSidak test in the event of a significant result to identify the source of statistical significance. When there were only 2 corresponding test groups, paired $t$-tests were used to detect differences. Data are presented as mean \pm standard error of the mean. Statistical analyses were performed using Primer of Biostatistics (Version 6.0, McGraw Hill, 2005). Significance was assigned at the $5 \%$ level.

\section{RESULTS}

Monocyte numbers and viability are shown (Table 1, Table 2). Cell numbers remained relatively constant following incubation at various temperatures, and viability was persistently higher than $91 \%$. There was no change in $\mathrm{pH}$ throughout the course of incubation.

Figure 1 depicts a quantitative analysis of HLA-DR MCF in $\mathrm{CD} 14^{+}$monocytes (lower right image). Appropriately matched isotype controls used to determine nonspecific binding thresholds are viewed in the lower left quadrant of the upper right image. The monocyte population is gated and surrounded by lymphocytes (below) and polymorphonuclear leukocytes (above) in the scatter plots (left images).

Following 2 hours of incubation at $37^{\circ} \mathrm{C}$, the change in HLA-DR MCF recorded was $2163 \pm$ 96 (Fig. 2). When corresponding samples were incubated at $40^{\circ} \mathrm{C}$, there was a $17 \%$ increase in recorded HLA-DR MCF to $2531 \pm 112(P<0.001)$. A corresponding decrease of $6 \%$ was observed following incubation at $34^{\circ} \mathrm{C}$ to $2031 \pm 92(P<0.01)$. The increasing HLA-DR intensity is qualitatively visualized in the images provided by the laser-scanning confocal microscope as incubation temperatures increased from 34 to $40^{\circ} \mathrm{C}$ (Fig. 3).

The initial rise in TNF- $\alpha$ concentration was similar for all temperatures at 30 minutes and 60 minutes (Fig. 4A). However, at 120 minutes, TNF- $\alpha$ concentrations were significantly lower at $40^{\circ} \mathrm{C}$ as compared with $34^{\circ} \mathrm{C}$ and $37^{\circ} \mathrm{C}(P<0.001)$. Specifically, mean changes in TNF- $\alpha$ levels between 60 minutes and 120 minutes at $34^{\circ} \mathrm{C}, 37^{\circ} \mathrm{C}$, and $40^{\circ} \mathrm{C}$ were $+18 \%,+13 \%$, and $-22 \%$, respectively, with a delay in reaching peak concentration at $34^{\circ} \mathrm{C}$ and $37^{\circ} \mathrm{C}(>120$ minutes) as compared with $40^{\circ} \mathrm{C}(<120$ minutes). A significant difference in TNF- $\alpha$ levels was observed at 240 minutes between $34^{\circ} \mathrm{C}$ and $40^{\circ} \mathrm{C}$ samples only $(P<0.01)$, due to an increase in the rate of TNF- $\alpha$ clearance at $37^{\circ} \mathrm{C}$.

When supernatant samples were analyzed for TNF- $\alpha$ at 2 hours only during independent HLADR MCF experiments, the results were similar to those obtained during the cytokine timecourse analysis experiments (Fig. 4B). However, an additional small difference in TNF- $\alpha$ concentration was detected between $34^{\circ} \mathrm{C}$ and $37^{\circ} \mathrm{C}(P<0.05)$, indicating a true inverse correlation between TNF- $\alpha$ concentration and temperature at 2 hours. 
The rise in IL-10 levels was significantly attenuated at all time-intervals at $37^{\circ} \mathrm{C}$ as compared with $34^{\circ} \mathrm{C}$ and $40^{\circ} \mathrm{C}$ (Fig. 5). Most notably, at 120 minutes and 240 minutes, IL-10 concentrations at $37^{\circ} \mathrm{C}$ were significantly lower than both $34^{\circ} \mathrm{C}$ and $40^{\circ} \mathrm{C}(P<0.001)$. IL-10 concentrations at $34^{\circ} \mathrm{C}$ and $40^{\circ} \mathrm{C}$ were largely similar, apart from a marginally significant, short-lived difference, at 120 minutes $(P=0.024)$. Preliminary data to determine the optimal LPS dose are also shown (Fig. 6).

\section{DISCUSSION}

Monocyte antigen presentation, assessed by surface HLA-DR expression, is a significant component of the early innate immune response, which triggers the production of various important cytokines, results in enhanced phagocytosis, and initiates activation of the adaptive immune system. Our results indicate that monocyte HLA-DR expression is significantly depressed by hypothermia $\left(34^{\circ} \mathrm{C}\right)$ and enhanced by hyperthermia $\left(40^{\circ} \mathrm{C}\right)$, following endotoxin challenge and 2 hours of incubation in conditions of constant $\mathrm{pH}$, oxygen, glucose, and carbon dioxide concentrations (Fig. 2).

We believe the clarity and illustrative nature of Figure 3 confirms the influence of temperature on $\mathrm{CD} 14^{+}(\mathrm{A}, \mathrm{B}$, and C), HLA-DR (D, E, and F), and a likely example of monocyte antigen presentation in process $(\mathrm{F}$ and $\mathrm{I})$.

Monocyte HLA-DR antigen expression has been extensively studied in infection complicating trauma and major surgery. Previous studies had shown a direct correlation between surface expression and uncomplicated recovery following an insult such as major surgery or trauma. ${ }^{26-28}$ In a study involving critically injured patients by Hershman et al, a $20 \%$ to $40 \%$ reduction in monocyte HLA-DR expression was noted on admission. ${ }^{29}$ The authors were able to demonstrate that delayed recovery of surface HLA-DR expression was associated with the development of septic sequelae, with levels failing to recover altogether in patients who did not survive. Consequently, use of monocyte HLA-DR expression as an early prognostic marker and its incorporation in outcome predictive scores has since been described. ${ }^{30,31}$ Prior studies suggested that the observed level of HLA-DR depression in our results may be clinically relevant. ${ }^{25,32}$

Mechanisms by which hypothermia may reduce surface HLA-DR expression may include a generalized delay in kinetics of several intracellular cellular signaling pathways, in particular, the nuclear factor- $\mathrm{\kappa B}(\mathrm{NF}-\mathrm{\kappa B})$ pathway, which has been previously shown to be essential for an adequate HLA-DR response to LPS in antigen-presenting cells. ${ }^{25,33,34}$

We investigated the pattern of release of TNF- $\alpha$ from healthy LPS-activated monocytes. TNF$\alpha$ is an important mediator of host defense, without which survival is severely compromised. ${ }^{35}$ It is thought to be the first proinflammatory cytokine to be released in a cascade of mediators, and is released both locally and systemically. Its effects in the local circulation include an increase in vascular permeability, activation of lymphocytes (adaptive immune system), and reciprocal activation of macrophages, resulting in an enhancement of innate immune defense mechanisms. In the systemic circulation, TNF- $\alpha$ affects the hypothalamus to induce fever, the liver to produce acute phase proteins, and the bone marrow to produce polymorphonuclear leukocytes, which are subsequently mobilized into the circulation.

Although TNF- $\alpha$ plays a major role in activation and enhancement of immune mechanisms, it has also been arguably linked to host tissue injury and multiorgan dysfunction from many disparate and disagreeing reports Evidence for this pathologic role emerged in 1985, when pretreatment with antiserum to TNF- $\alpha$ was shown to protect mice against endotoxin lethality in vivo.36 Since then, the development and use of monoclonal TNF- $\alpha$ antibodies has led to similar findings in endotoxin-challenged animal models.37 Many human trials exploiting the 
use of TNF- $\alpha$ antibodies and soluble TNF- $\alpha$ receptors, which quench the cytokine, followed. However, no significant, reproducible reduction in mortality was observed as had been anticipated. ${ }^{38}$ Van der Poll later hypothesized that severely septic patients usually suffer from a state of "immunoparalysis," where secretion of proinflammatory cytokines, such as TNF- $\alpha$, occur in relatively short-lived bursts immediately following the insult, and are followed by prolonged "refractory" compensatory increases in anti-inflammatory (IL-10) cytokines, most notably IL-10. The authors proposed that the above trials had intercepted septic human subjects late into the phase of immunoparalysis, thereby failing to demonstrate survival benefit from antagonizing TNF- $\alpha .{ }^{39}$ Furthermore, they summarized that in human sepsis, where a focus for sepsis frequently exists, levels of proinflammatory cytokines remain localized, thereby avoiding systemic toxicity and playing a crucial role in the eradication of responsible pathogens nearby. 39

In separate studies, Fairchild et al were able to demonstrate a similar early "spike" pattern of release of proinflammatory cytokines, such as TNF- $\alpha .{ }^{40}$ However, their work was extended to demonstrate the effect of temperature change on the initial release pattern and demonstrated a short-lived burst release with hyperthermia but a more delayed and prolonged release at hypothermic conditions, which they later showed to be mediated by prolonged augmentation of cellular signals via NF-kB. ${ }^{41}$ The authors proposed that hypothermia may exert detrimental effects via the prolongation of proinflammatory cytokine release. Incidentally, a delayed but prolonged activation of the NF- $\mathrm{KB}$ pathway may also contribute to the simultaneous reduction in HLA-DR surface expression and prolonged TNF- $\alpha$ release.

In our in vitro model, which uses a $1 \mathrm{ng} / \mathrm{mL}$ LPS challenge to emulate the introduction of an intraoperative bacterial load, we were able to demonstrate the TNF- $\alpha$ pattern previously described, with an initial rise in concentration followed by rapid degradation after 120 minutes (Fig. 4A). However, a failure to eliminate TNF- $\alpha 120$ minutes following the insult is clearly visible at $34^{\circ} \mathrm{C}$ or $37^{\circ} \mathrm{C}$ compared with $40^{\circ} \mathrm{C}$. This was subsequently confirmed in experiments examining cytokine production at 120 minutes alone, which went a step further to demonstrate a true inverse correlation between TNF- $\alpha$ concentration and temperature (Fig. 4B).

The importance of this result lies in the ability to link this, and previous findings, with clinical complications attributed to hypothermia. A "bell-shaped" release curve of TNF- $\alpha$ is seen, with a delay in TNF- $\alpha$ clearance with hypothermia as previously described. ${ }^{39,40}$ This may be important to several surgical hypothermic complications. For example, acute phase proteins, which are released from the liver by TNF- $\alpha$ and other proinflammatory cytokines, are thought to increase predisposition to myocardial complications, such as myocardial infarction.

Therefore, an exaggerated release of acute phase proteins due to delayed TNF- $\alpha$ clearance, which, in turn, occurs due to hypothermia, may, in part, explain the 3-fold increased myocardial complication rate observed by Frank et al. ${ }^{5}$ Interestingly, TNF- $\alpha$ over-expression has recently been shown to induce cardiac myocyte hypertrophy, dysfunctional dilatation, and apoptosis in transgenic animal models, which may also be important in this context, ${ }^{42,43}$ as the capacity to increase cardiac output has long been clinically recognized to be associated with improved survival from septic challenges. ${ }^{44}$ Other hypothermic complications such as wound infection, generalized sepsis, and coagulopathy may also be in part explained by the direct prolongation of TNF- $\alpha$ release, or by heightened compensatory responses that may follow. ${ }^{31}$

Interestingly, TNF- $\alpha$ clearance at $34^{\circ} \mathrm{C}$ and $37^{\circ} \mathrm{C}$ were very similar. However, it is important to remember that TNF- $\alpha$ secretion ordinarily causes fever, and, thus, clearance would normally be expected to follow the hyperthermic trend. Furthermore, maximal levels of TNF- $\alpha$ attained at $40^{\circ} \mathrm{C}$ during the proinflammatory phase, which has previously been linked to early mortality in sepsis, ${ }^{39}$ are approximately $21 \%$ lower than at either $34^{\circ} \mathrm{C}$ or $37^{\circ} \mathrm{C}$. Worryingly, this may reaffirm evidence that antipyretic therapy aimed at restoring normal body temperature during 
the initial phases of a febrile insult may detrimentally delay TNF- $\alpha$ clearance, thereby impairing an important adaptive response, as previously implicated by Kluger et al. ${ }^{45}$

IL-10 is an anti-inflammatory cytokine, which acts on monocytes to limit TNF- $\alpha$ release following the initial proinflammatory surge. Levels of IL-10 therefore demonstrate a gradual and persistent rise with time at all temperatures, although this is persistently attenuated at $37^{\circ}$ $\mathrm{C}$ compared with $34^{\circ} \mathrm{C}$ and $40^{\circ} \mathrm{C}$ (Fig. 5). Although this may seem odd at first, these results demonstrate at least 3 major important points. First, the results prove that the cells are active and capable of cytokine production after several hours, which adds ground to a model with limitations compared with in vivo and human models. Secondly, the pattern of IL-10 release is similar to previously described models, and demonstrate, in particular, the anticipated onset of the alleged anti-inflammatory phase. ${ }^{39}$ Thirdly, and most importantly, the onset of this antiinflammatory phase, expressed as a product of IL- 10 concentration, begins once TNF- $\alpha$ levels, and therefore, body temperature has been restored to $37^{\circ} \mathrm{C}$. Thus, a return to normal body temperature following febrile infection may provide a mechanism by which the "refractory" response is minimized, as evidenced by attenuation of IL-10 release. This previously undescribed phenomenon may suggest a further evolutionary mechanism, which is, as yet, not clearly appreciated or understood. In this setting, a persistently elevated temperature, or excessive cooling to lower preceding fever, may disrupt a natural, intricately synchronized regulatory mechanism, which serves to ensure pathogen elimination and host survival. Remarkably, Lekkou et al described early elevated levels of IL-10 as an independent risk factor for mortality in septic patients. ${ }^{31}$

Although it has been extensively argued whether various cytokines ultimately exert beneficial or detrimental effects in human disease, we believe that the pattern of cytokine secretion is more important, which is regulated by intricate and highly complex interactions. This probably applies to global immune function in general. Nevertheless, the balance between pro and antiinflammatory processes and their time courses in an individual experiment or patient has been the subject of extensive, but vastly conflicting studies, which we have attempted to summarize in this discussion; its clinical importance remains to be determined.

While the detrimental effects of hypothermia continue to be intensively investigated, new avenues exploiting the protective effects of fever are emerging. Hyperthermia has been shown to enhance immune defense mechanisms, ${ }^{46,47}$ protect cells of the immune system against toxic cytokines, 48 and potentially limit prolonged activation of immune defense mechanisms.40,

${ }^{49}$ Interestingly, direct microbial sensitivity to hyperthermia rarely accounts for bacterial killing. Recent studies demonstrating enhanced macrophage function mediated by heat shock protein (HSP) in hyperthermia, direct heat-induced tumor cell cytotoxicity and hyperthermic radio-chemo-sensitization of tumor cells have led to new early-stage clinical immunologic cancer therapies, which have shown early promise and are now on the rise. ${ }^{50,51}$

\section{CONCLUSION}

Perioperative hypothermia has recently been associated with a poorer outcome following surgery. Previous cellular mechanisms in this context have included reduced antigen phagocytosis, and tissue hypoxia secondary to hypothermic vasoconstriction. In this report, we provide 3 further mechanisms by which hypothermia exerts detrimental effects on surgical patients. Hypothermia results in reduced monocyte HLA-DR surface expression, delayed clearance of TNF- $\alpha$, and increased IL-10 release. These findings may provide an intermediate link for mechanisms by which complications such as sepsis, surgical site infection, coagulopathy, and morbid cardiac events may occur. An appreciation that hypothermia exerts several deleterious immunologic changes must signal a warning to all physicians involved in the care of surgical patients, to minimize the incidence of complications associated with this 
avoidable condition. A substantial degree of guidance and supervision were provided by our laboratory manager, the late Mr. James D. Pietsch, who will be dearly missed.

\section{Acknowledgments}

The authors thank Susan Galandiuk for her valuable advice throughout the course of the study, Dr. Jeff Falcone for his guidance in setting up confocal microscopy, Dr. Andreas Lenz for his assistance with the reproduction of flow cytometry images, Mr. David Brown for his help in conducting early pilot studies, and Ms. Margaret Abby for her editorial input.

\section{REFERENCES}

1. Kluger, MJ. Fever-its Biology, Evolution, and Function. Princeton, NJ: Princeton University Press; 1979.

2. Hasday JD, Fairchild KD, Shanholtz C. The role of fever in the infected host. Microbes Infect 2000;2:1891-1904. [PubMed: 11165933]

3. Kurz A. Thermal care in the perioperative period. Best Pract Res Clin Anaesthesiol 2008;22:39-62. [PubMed: 18494388]

4. Kurz A, Sessler DI, Lenhardt R. Study of Wound Infection and Temperature Group. Perioperative normothermia to reduce the incidence of surgical-wound infection and shorten hospitalization. N Engl J Med 1996;334:1209-1215. [PubMed: 8606715]

5. Frank SM, Fleisher LA, Breslow MJ, et al. Perioperative maintenance of normothermia reduces the incidence of morbid cardiac events: a randomized clinical trial. JAMA 1997;277:1127-1134. [PubMed: 9087467]

6. Luna GK, Maier RV, Pavlin EG, et al. Incidence and effect of hypothermia in seriously injured patients. J Trauma 1987;27:1014-1018. [PubMed: 3656463]

7. Schmied H, Kurz A, Sessler DI, et al. Mild hypothermia increases blood loss and transfusion requirements during total hip arthroplasty. Lancet 1996;347:289-292. [PubMed: 8569362]

8. Lenhardt R, Marker E, Goll V, et al. Mild intraoperative hypothermia prolongs postanesthetic recovery. Anesthesiology 1997;87:1318-1323. [PubMed: 9416715]

9. Carli F, Emery PW, Freemantle CA. Effect of peroperative normothermia on postoperative protein metabolism in elderly patients undergoing hip arthroplasty. Br J Anaesth 1989;63:276-282. [PubMed: 2803885]

10. Kurz A, Plattner O, Sessler DI, et al. The threshold for thermoregulatory vasoconstriction during nitrous oxide/isoflurane anesthesia is lower in elderly than in young patients. Anesthesiology 1993;79:465-469. [PubMed: 8363070]

11. Peng RY, Bongard FS. Hypothermia in trauma patients. J Am Coll Surg 1999;188:685-696. [PubMed: 10359364]

12. Polk HC Jr, Lopez-Mayor JF. Postoperative wound infection: a prospective study of determinant factors and prevention. Surgery 1969;66:97-103. [PubMed: 4892316]

13. Mahid SS, Polk HC Jr, Lewis JN, et al. Opportunities for improved performance in surgical specialty practice. Ann Surg 2008;247:380-388. [PubMed: 18216548]

14. van den Berghe G, Wouters P, Weekers F, et al. Intensive insulin therapy in the critically ill patients. N Engl J Med 2001;345:1359-1367. [PubMed: 11794168]

15. Allen DB, Maguire JJ, Mahdavian M, et al. Wound hypoxia and acidosis limit neutrophil bacterial killing mechanisms. Arch Surg 1997;132:991-996. [PubMed: 9301612]

16. Greif R, Akca O, Horn EP, et al. Outcomes Research Group. Supplemental perioperative oxygen to reduce the incidence of surgical-wound infection. N Engl J Med 2000;342:161-167. [PubMed: 10639541]

17. Hopf HW, Hunt TK, West JM, et al. Wound tissue oxygen tension predicts the risk of wound infection in surgical patients. Arch Surg 1997;132:997-1004. [PubMed: 9301613]

18. Leijh PC, van den Barselaar MT, van Zwet TL, et al. Kinetics of phagocytosis of Staphylococcus aureus and Escherichia coli by human granulocytes. Immunology 1979;37:453-465. [PubMed: 381182] 
19. van Oss CJ, Absolom DR, Moore LL, et al. Effect of temperature on the chemotaxis, phagocytic engulfment, digestion, and $\mathrm{O} 2$ consumption of human polymorphonuclear leukocytes. J Reticuloendothel Soc 1980;27:561-565. [PubMed: 7392012]

20. Wenisch C, Narzt E, Sessler DI, et al. Mild intraoperative hypothermia reduces production of reactive oxygen intermediates by polymorphonuclear leukocytes. Anesth Analg 1996;82:810-816. [PubMed: 8615502]

21. Miles AA, Miles EM, Burke J. The value and duration of defence reactions of the skin to the primary lodgement of bacteria. Br J Exp Pathol 1957;38:79-96. [PubMed: 13413084]

22. Polk HC, Miles AA. The decisive period in the primary infection of muscle by Escherichia coli. $\mathrm{Br}$ J Exp Pathol 1973;54:99-109. [PubMed: 4570251]

23. Oehler R, Pusch E, Dungel P, et al. Glutamine depletion impairs cellular stress response in human leucocytes. Br J Nutr 2002;87:S17-S21. [PubMed: 11895151]

24. Hirohashi N, Morrison DC. Low-dose lipopolysaccharide (LPS) pretreatment of mouse macrophages modulates LPS-dependent interleukin-6 production in vitro. Infect Immun 1996;64:1011-1015. [PubMed: 8641750]

25. Turina M, Miller FN, Tucker CF, et al. Short-term hyperglycemia in surgical patients and a study of related cellular mechanisms. Ann Surg 2006;243:845-851. [PubMed: 16772788]

26. Ditschkowski M, Kreuzfelder E, Rebmann V, et al. HLA-DR expression and soluble HLA-DR levels in septic patients after trauma. Ann Surg 1999;229:246-254. [PubMed: 10024107]

27. Livingston DH, Appel SH, Wellhausen SR, et al. Depressed interferon gamma production and monocyte HLA-DR expression after severe injury. Arch Surg 1988;123:1309-1312. [PubMed: 3140765]

28. Polk HC Jr, George CD, Wellhausen SR, et al. A systematic study of host defense processes in badly injured patients. Ann Surg 1986;204:282-299. [PubMed: 3019260]

29. Hershman MJ, Cheadle WG, Wellhausen SR, et al. Monocyte HLA-DR antigen expression characterizes clinical outcome in the trauma patient. Br J Surg 1990;77:204-207. [PubMed: 2317682]

30. Hershman MJ, Cheadle WG, Kuftinec D, et al. An outcome predictive score for sepsis and death following injury. Injury 1988;19:263-266. [PubMed: 3229842]

31. Lekkou A, Karakantza M, Mouzaki A, et al. Cytokine production and monocyte HLA-DR expression as predictors of outcome for patients with community-acquired severe infections. Clin Diagn Lab Immunol 2004;11:161-167. [PubMed: 14715564]

32. Cheadle WG, Hershman MJ, Wellhausen SR, et al. HLA-DR antigen expression on peripheral blood monocytes correlates with surgical infection. Am J Surg 1991;161:639-645. [PubMed: 1862821]

33. Ardeshna KM, Pizzey AR, Devereux S, et al. The PI3 kinase, p38 SAP kinase, and NF- $\kappa B$ signal transduction pathways are involved in the survival and maturation of lipopolysaccharide-stimulated human monocyte-derived dendritic cells. Blood 2000;96:1039-1046. [PubMed: 10910920]

34. Dandona P, Aljada A, Mohanty P, et al. Insulin inhibits intranuclear nuclear factor $\kappa \mathrm{B}$ and stimulates $\kappa \mathrm{B}$ in mononuclear cells in obese subjects: evidence for an anti-inflammatory effect? J Clin Endocrinol Metab 2001;86:3257-3265. [PubMed: 11443198]

35. van der Poll T, Keogh CV, Buurman WA, et al. Passive immunization against tumor necrosis factoralpha impairs host defense during pneumococcal pneumonia in mice. Am J Respir Crit Care Med 1997;155:603-608. [PubMed: 9032201]

36. Beutler B, Milsark IW, Cerami AC. Passive immunization against cachectin/tumor necrosis factor protects mice from lethal effect of endotoxin. Science 1985;229:869-871. [PubMed: 3895437]

37. Tracey KJ, Fong Y, Hesse DG, et al. Anti-cachectin/TNF monoclonal antibodies prevent septic shock during lethal bacteraemia. Nature 1987;330:662-664. [PubMed: 3317066]

38. Arndt P, Abraham E. Immunological therapy of sepsis: experimental therapies. Intensive Care Med 2001;27:S104-S115. [PubMed: 11307366]

39. van der Poll T. Immunotherapy of sepsis. Lancet Infect Dis 2001;1:165-174. [PubMed: 11871493]

40. Fairchild KD, Viscardi RM, Hester L, et al. Effects of hypothermia and hyperthermia on cytokine production by cultured human mononuclear phagocytes from adults and newborns. J Interferon Cytokine Res 2000;20:1049-1055. [PubMed: 11152570] 
41. Fairchild KD, Singh IS, Patel S, et al. Hypothermia prolongs activation of NF- $\kappa B$ and augments generation of inflammatory cytokines. Am J Physiol Cell Physiol 2004;287:C422-C431. [PubMed: 15070815]

42. Bozkurt B, Kribbs SB, Clubb FJ Jr, et al. Pathophysiologically relevant concentrations of tumor necrosis factor-alpha promote progressive left ventricular dysfunction and remodeling in rats. Circulation 1998;97:1382-1391. [PubMed: 9577950]

43. Kubota T, McTiernan CF, Frye CS, et al. Dilated cardiomyopathy in transgenic mice with cardiacspecific overexpression of tumor necrosis factor-alpha. Circ Res 1997;81:627-635. [PubMed: 9314845]

44. Clowes GH Jr, O’Donnell TF Jr, Ryan NT, et al. Energy metabolism in sepsis: treatment based on different patterns in shock and high output stage. Ann Surg 1974;179:684-696. [PubMed: 4823845]

45. Kluger MJ, Kozak W, Conn CA, et al. The adaptive value of fever. Infect Dis Clin North Am 1996;10:1-20. [PubMed: 8698984]

46. Jiang Q, Cross AS, Singh IS, et al. Febrile core temperature is essential for optimal host defense in bacterial peritonitis. Infect Immun 2000;68:1265-1270. [PubMed: 10678936]

47. Pritchard MT, Wolf SF, Kraybill WF, et al. The anti-tumor effect of interleukin-12 is enhanced by mild (fever-range) thermal therapy. Immunol Invest 2005;34:361-380. [PubMed: 16136786]

48. Oehler R, Pusch E, Zellner M, et al. Cell type-specific variations in the induction of hsp70 in human leukocytes by feverlike whole body hyperthermia. Cell Stress Chaperones 2001;6:306-315. [PubMed: 11795467]

49. Ostberg JR, Repasky EA. Emerging evidence indicates that physiologically relevant thermal stress regulates dendritic cell function. Cancer Immunol Immunother 2006;55:292-298. [PubMed: 15864585]

50. Milani V, Noessner E. Effects of thermal stress on tumor antigenicity and recognition by immune effector cells. Cancer Immunol Immunother 2006;55:312-319. [PubMed: 16151807]

51. Peng JC, Hyde C, Pai S, et al. Monocyte-derived DC primed with TLR agonists secrete IL-12p70 in a CD40-dependent manner under hyperthermic conditions. J Immunother 2006;29:606-615.

[PubMed: 17063123] 

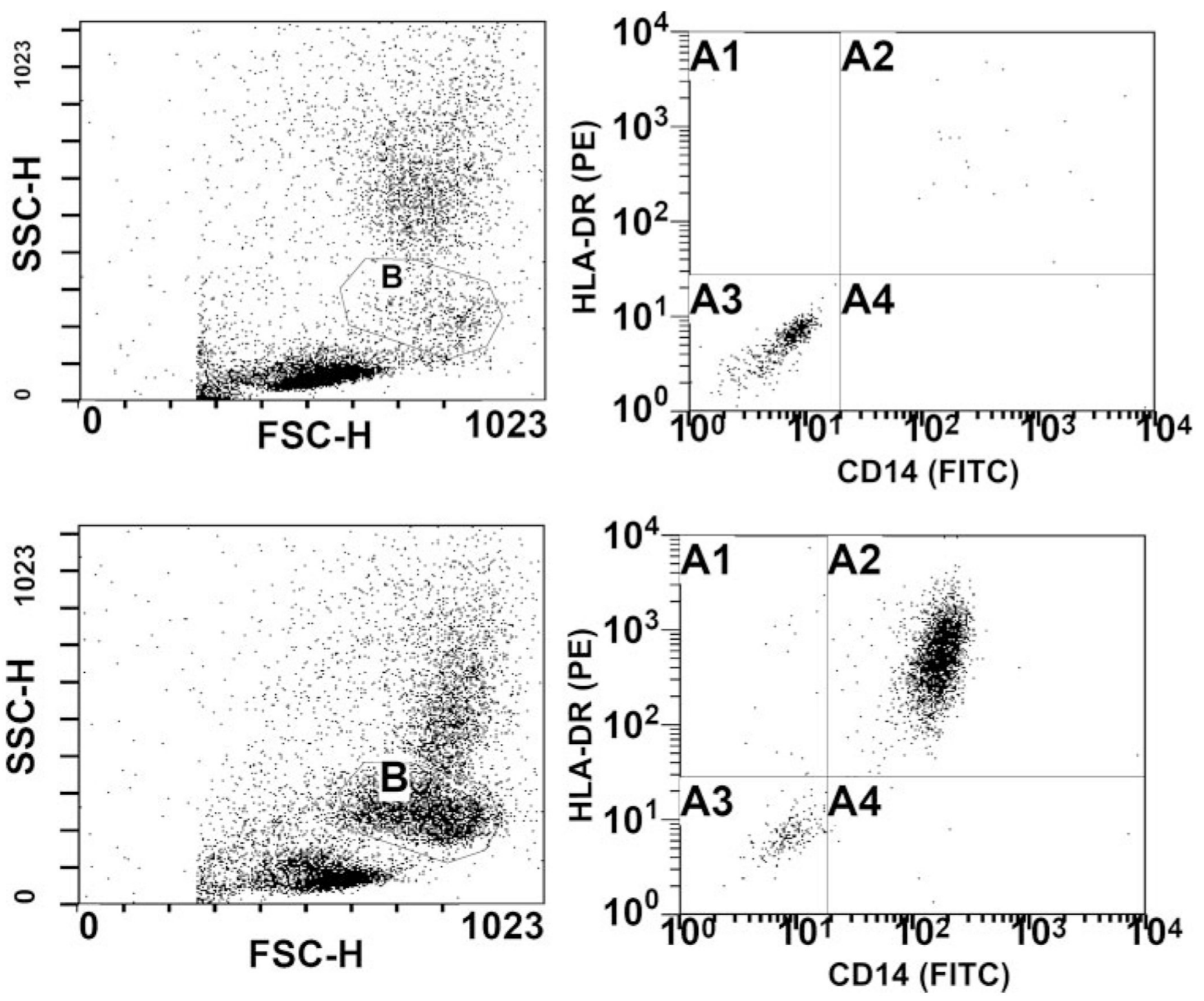

FIGURE 1.

Flow cytometer scatter plots showing negative control (upper image-A3) and positive CD14+HLA-DR (lower image-A2) stained monocytes (gated-B). 


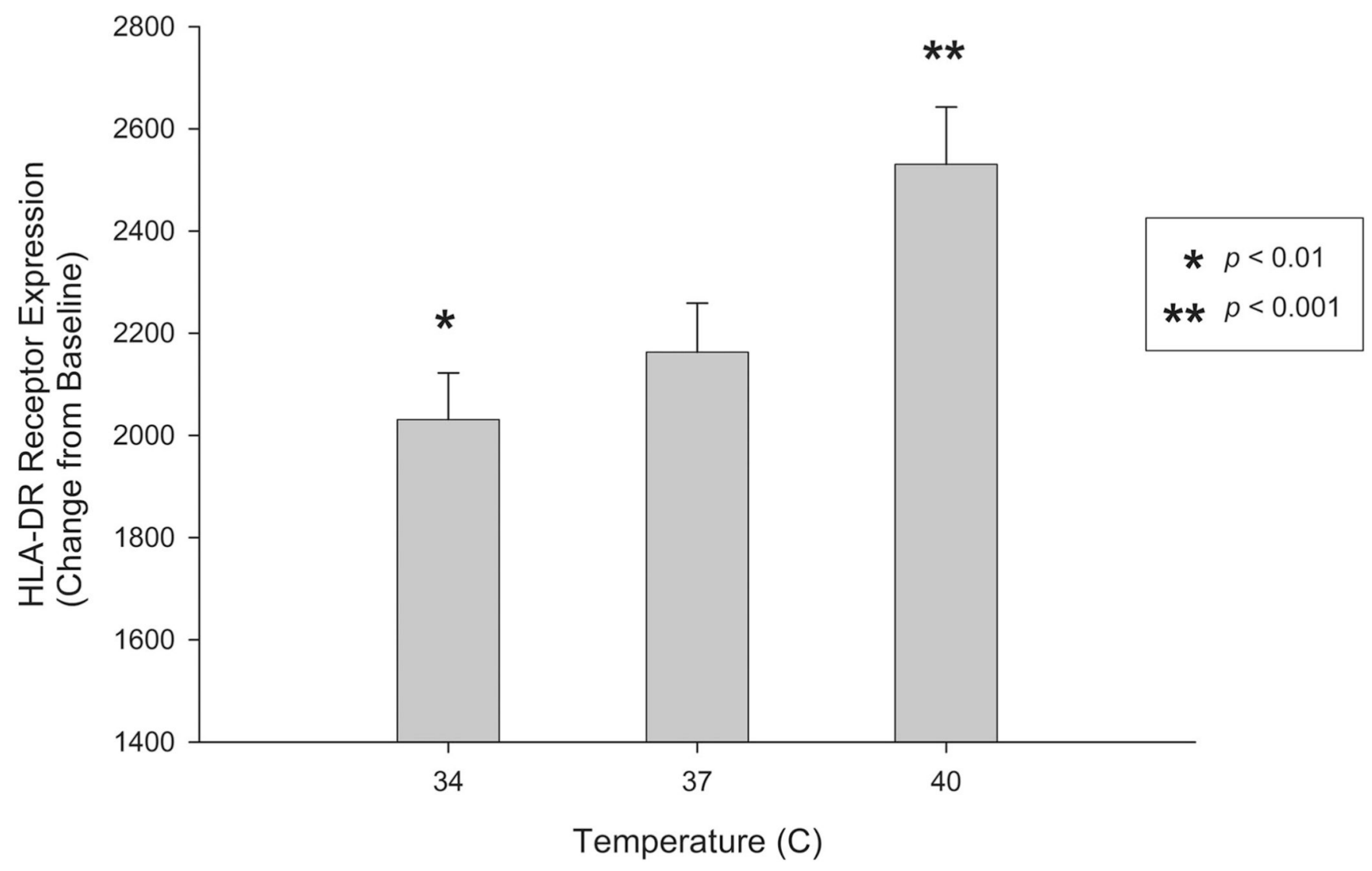

FIGURE 2 .

Effect of temperature on change in HLA-DR MCF $(n=13)$. 

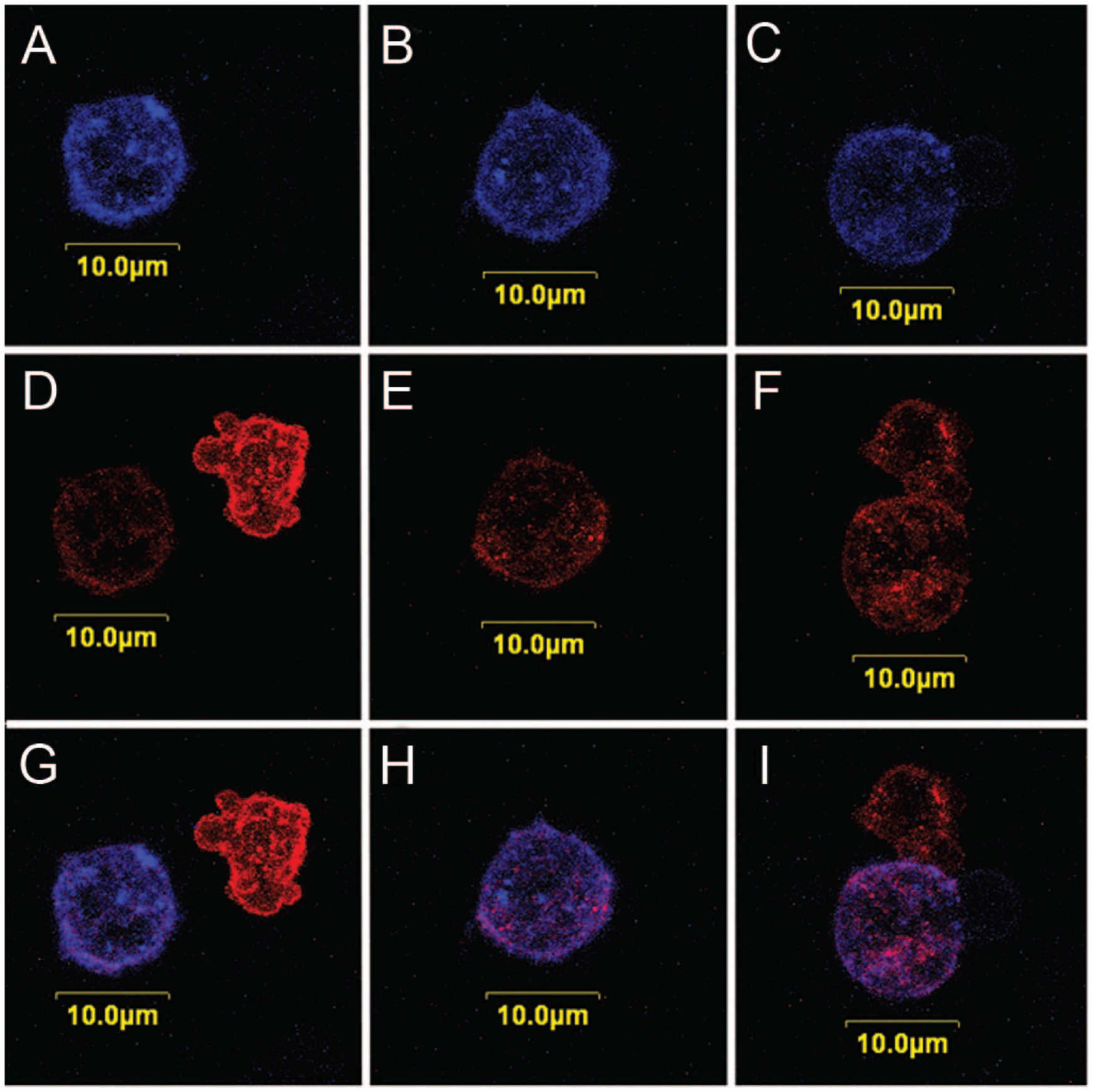

FIGURE 3.

Multiline Argon laser-scanning confocal microscopy digital images (Columns: $34^{\circ} \mathrm{C}-$ left; $37^{\circ}$ $\mathrm{C}$-middle; $40^{\circ} \mathrm{C}$-right). Blue fluorescence represents fluorescein isothiocyanate-labeled $\mathrm{CD} 14^{+}$staining (A, B, and C). Red represents phycoerythrin-labeled HLA-DR (D, E, and F). Magenta represents co-localized staining which indicates surface HLA-DR since blue $\mathrm{CD}_{14}{ }^{+}$exists only on the cell surface (G, H, and I). Red HLA-DR fluorescence intensity increases with increasing temperature (D, E, and F). A change in fluorescence color from blue to magenta with increasing temperature, therefore, specifically indicates an increase in surface HLA-DR expression. Note, at $40^{\circ} \mathrm{C}$, a greater intensity of internalized HLA-DR (red) can be seen. This represents HLA-DR down-regulation since the stain is naturally incapable of 
permeating the cell membrane prior to binding. Therefore, actual surface HLA-DR receptor expression is considerably higher than estimated by flow cytometry at $40^{\circ} \mathrm{C}$, when accounting for inevitable down-regulation of surface HLA-DR during monocyte preparation. In images $\mathrm{D}, \mathrm{F}, \mathrm{G}$, and I, adjacent lymphocytes (red only) are visible (HLA-DR positive/CD $14^{+}$negative). Images $\mathrm{F}$ and I may represent monocyte antigen presentation in progress. 

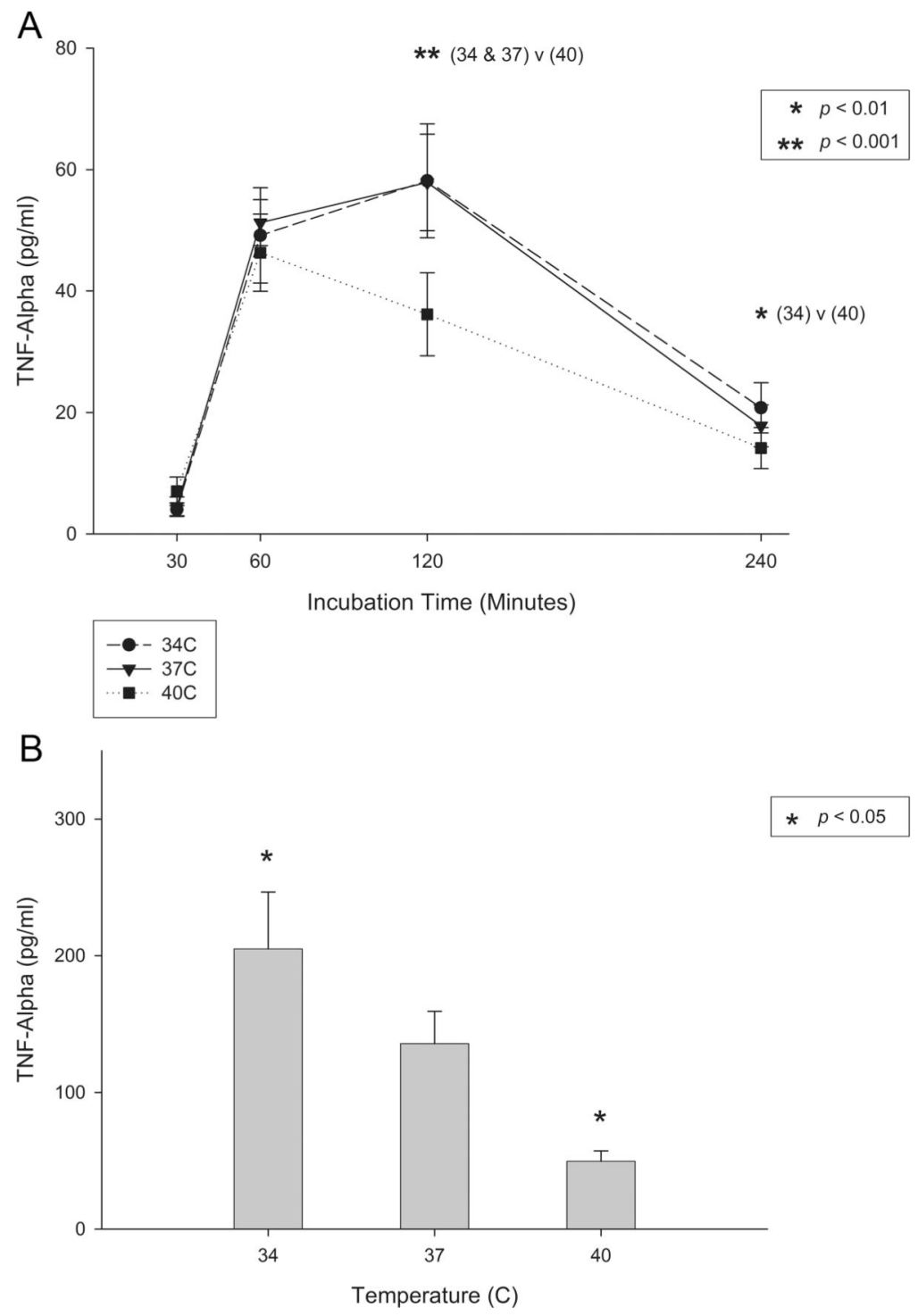

FIGURE 4.

A and B, The effect of temperature on LPS-induced TNF- $\alpha(\mathrm{pg} / \mathrm{mL})$ release at $30,60,120$, and 240 minutes $(\mathrm{A})$ and 120 minutes only $(\mathrm{B}, \mathrm{n}=9)$. 


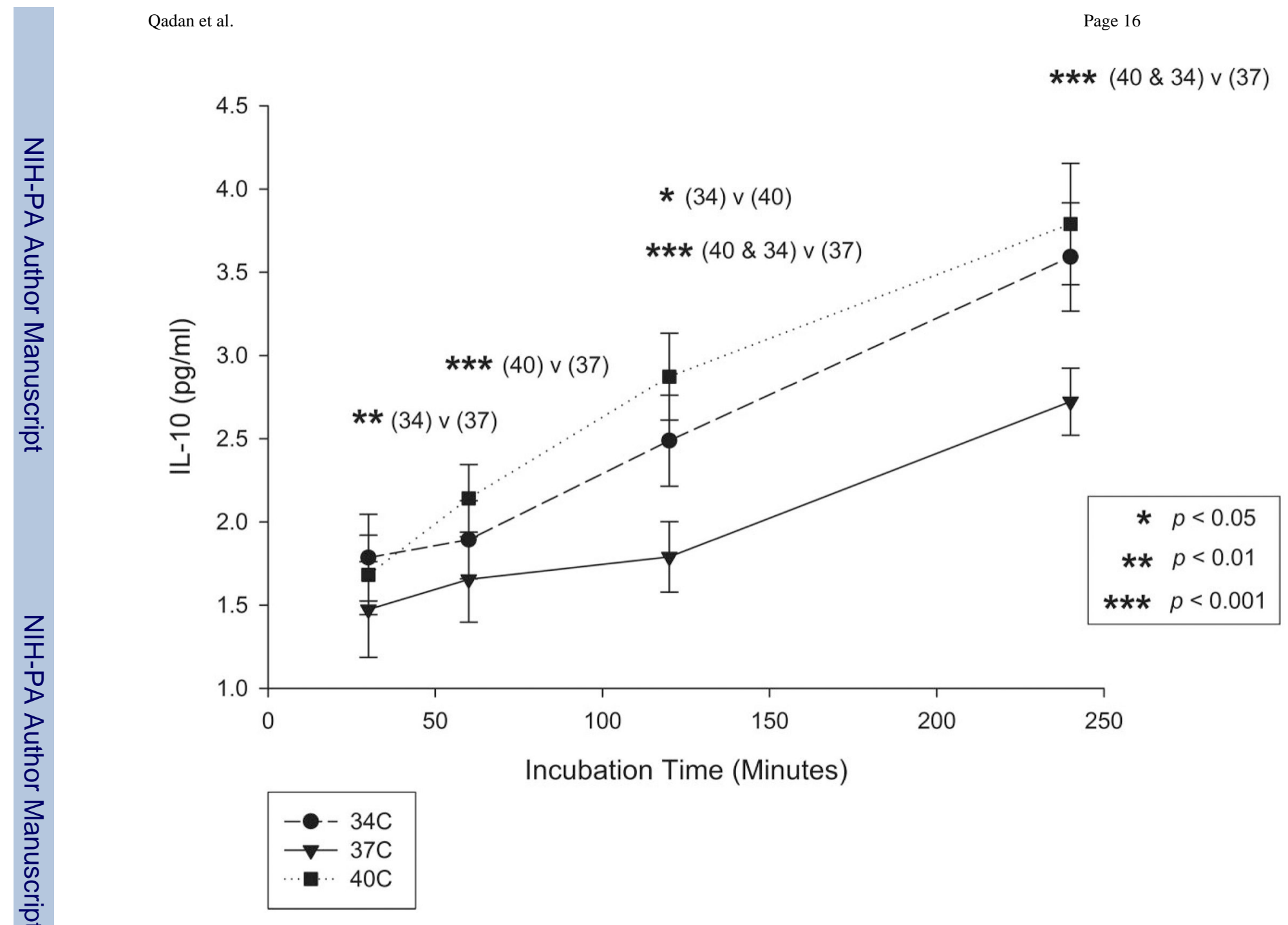

FIGURE 5.

The effect of temperature on LPS-induced IL-10 release at 30, 60, 120, and 240 minutes $(\mathrm{n}=$ 9). 


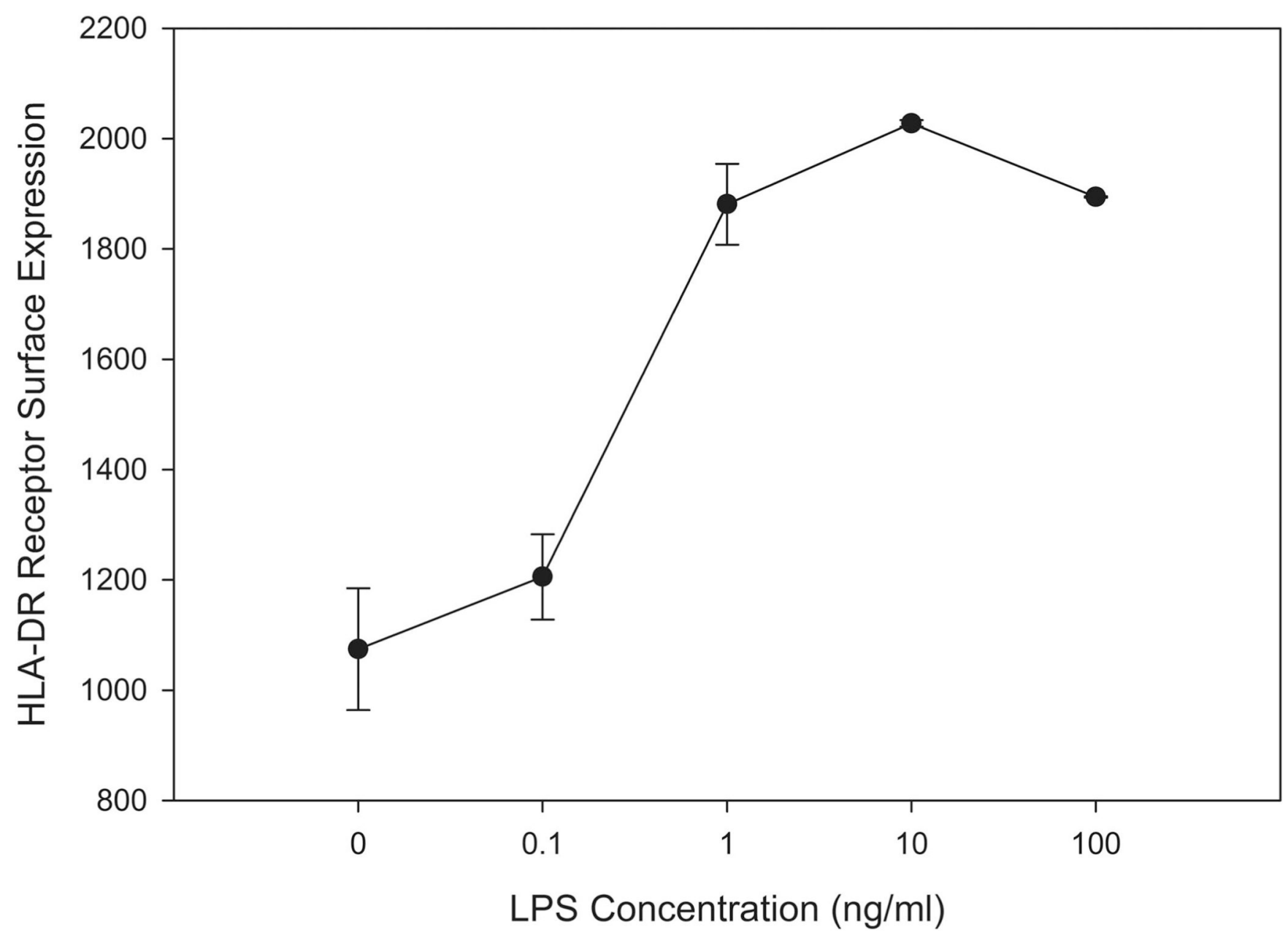

FIGURE 6.

Lipopolysaccharide (LPS) dose-response curves on HLA-DR MCF showing maximal fluorescence at $1 \mathrm{ng} / \mathrm{mL}$ LPS following 2 hours of incubation $(\mathrm{n}=2)$. 


\section{TABLE 1}

Hemocytometer Manual White Cell Counts Following 2 and 4 Hours Incubations at $34^{\circ} \mathrm{C}, 37^{\circ} \mathrm{C}$, and $40^{\circ} \mathrm{C}^{*}$

\begin{tabular}{lcc}
\hline Sample & Manual White Cell Count & Actual White Cell Count \\
\hline Time 0 & 104 & $5.20 \times 10^{6}$ \\
$34^{\circ} \mathrm{C}-2 \mathrm{~h}$ & 104 & $5.20 \times 10^{6}$ \\
$37^{\circ} \mathrm{C}-2 \mathrm{~h}$ & 112 & $5.60 \times 10^{6}$ \\
$40^{\circ} \mathrm{C}-2 \mathrm{~h}$ & 119 & $5.95 \times 10^{6}$ \\
Time 0 & 110 & $5.50 \times 10^{6}$ \\
$34^{\circ} \mathrm{C}-4 \mathrm{~h}$ & 103 & $5.15 \times 10^{6}$ \\
$37^{\circ} \mathrm{C}-4 \mathrm{~h}$ & 102 & $5.10 \times 10^{6}$ \\
$40^{\circ} \mathrm{C}-4 \mathrm{~h}$ & 104 & $5.20 \times 10^{6}$ \\
\hline$*$ &
\end{tabular}


